\title{
Role of Vascular Endothelial Growth Factor in Bone Marrow Stromal Cell Modulation of Endothelial Cells
}

\author{
DARNELL KAIGLER, D.D.S., ${ }^{1}$ PAUL H. KREBSBACH, D.D.S., Ph.D., 2 \\ PETER J. POLVERINI, D.D.S., D.M.Sc., ${ }^{3}$ and DAVID J. MOONEY, Ph.D. ${ }^{1,4}$
}

\begin{abstract}
One of the fundamental principles that underlies tissue-engineering strategies using cell transplantation is that a newly formed tissue must acquire and maintain sufficient vascularization in order to support its growth. Enhancing angiogenesis through delivery of growth factors is one approach to establishing a vascular network to these tissues. In this study, we tested the potential of bone marrow stromal cells (BMSCs) to modulate the growth and differentiation activities of blood vessel precursors, endothelial cells (ECs), by their secretion of soluble angiogenic factors. The growth and differentiation of cultured ECs were enhanced in response to exposure to BMSC conditioned medium (CM). Enzyme-linked immunosorbent assays demonstrated that both mouse and human BMSCs secreted significant quantities of vascular endothelial growth factor (VEGF) (2.4-3.1 ng/106 cells per day). Furthermore, eliminating the activity of BMSC-secreted VEGF with blocking antibodies completely blocked the CM effects on cultured ECs. These data demonstrate that human BMSCs secrete sufficient quantities of VEGF to enhance survival and differentiation of endothelial cells in vitro, and suggest they may be capable of directly orchestrating angiogenesis in vivo.
\end{abstract}

\section{INTRODUCTION}

$\mathbf{T}$ The STUdy of tissue engineering has developed in response to an inadequate supply of organs and tissues for patients requiring organ/tissue replacement. ${ }^{1}$ One of the principal objectives of this rapidly evolving field is to recreate functional, healthy tissues and organs in order to replace tissue lost to disease or inherited deficiencies. Transplantation of selected cell populations is a major approach to engineering a number of tissue types. However, the survival of transplanted cells is dependent on diffusion of nutrients and waste products between the transplanted cells and the vasculature in the surrounding host tissue. It has been well established that a functional vasculature is an essential component of any metaboli- cally active tissue that has a thickness in excess of a few millimeters. ${ }^{2}$ It is the limitations of this mass transport of nutrients that can lead to loss of more than $95 \%$ of certain transplanted cell types. ${ }^{3}$ This mass transport issue, furthermore, limits the size of engineered tissues to a millimeter scale, which is clinically insufficient if one is to replace a large mass of tissue or a whole organ. To overcome these limitations, a vascular network must be established throughout the newly formed tissue in order to support its growth.

The rapid and transient growth of new capillaries, the process called angiogenesis, is central to most human life processes including tissue development, regeneration, and repair. ${ }^{4}$ A variety of growth factors that promote the formation of a new microvasculature have been identi-

\footnotetext{
${ }^{1}$ Department of Biologic and Materials Sciences, University of Michigan, Ann Arbor, Michigan.

${ }^{2}$ Department of Oral Medicine/Pathology/Oncology, University of Michigan, Ann Arbor, Michigan.

${ }^{3}$ University of Minnesota School of Dentistry, Minneapolis, Minnesota.

${ }^{4}$ Department of Chemical and Biomedical Engineering, University of Michigan, Ann Arbor, Michigan.
} 
fied, ${ }^{5,6}$ and they could potentially be utilized to accelerate the ingrowth of blood vessels in developing tissue. Among these factors, vascular endothelial growth factor (VEGF) shows promise as a molecule that may enhance the vascularization of engineered tissue, as it has been shown to act most specifically on endothelial cells (ECs). ${ }^{7}$ Currently, VEGF is being employed in different model systems to examine its effects on revascularization of ischemic tissues and musculocutaneous flaps. ${ }^{8,9}$ The routes of administration of VEGF in these systems varies from systemic administration to localized delivery. Other potential therapeutic uses of VEGF include its use in systems for delivery of growth factors from different types of polymers. ${ }^{10-12}$

Interestingly, there is current evidence to suggest that osteogenic cells and certain types of bone marrowderived cells can themselves produce the angiogenic mediator VEGF. ${ }^{13,14}$ This observation raises the possibility that these mesenchymal cells could potentially regulate angiogenesis. Multipotent cells derived from bone marrow are fast becoming a popular choice as a source of osteoprogenitor cells for tissue engineering bone. ${ }^{15-17} \mathrm{In}$ cell cultures generated from suspensions of marrow, colonies form from a single precursor cell termed the colony-forming-unit fibroblast (CFU-F). ${ }^{18,19}$ The progeny of these CFU-F are what have been defined as bone marrow stromal cells (BMSCs). These BMSCs are ca- pable of extensive proliferation and differentiation into several phenotypes including bone, cartilage, fibrous tissue, adipose tissue, and hematopoiesis-supporting reticular stroma, ${ }^{20}$ and represent a heterogeneous cell population likely containing a range of progenitor cells. Mesenchymal stem cells (MSCs) similarly are derived from bone marrow but are isolated from marrow aspirates after purification by Percoll density gradient centrifugation. ${ }^{21}$ Both of these cell populations have potential applications in tissue repair strategies..$^{20,22}$

The hypothesis underlying the current study is that BMSCs can direct and modulate the growth and differentiation of ECs. The specific goals of the present study were to determine whether BMSCs produce angiogenic factors capable of enhancing the proliferation and differentiation of endothelial cells. The results of these studies indicate that BMSCs secrete sufficient quantities of VEGF to enhance the growth and differentiation of endothelial cells in an in vitro model of angiogenesis.

\section{MATERIALS AND METHODS}

\section{Isolation and culture of BMSCs and MC3T3-E1 cells}

Human bone marrow was collected, with University of Michigan institutional review board approval as pre-

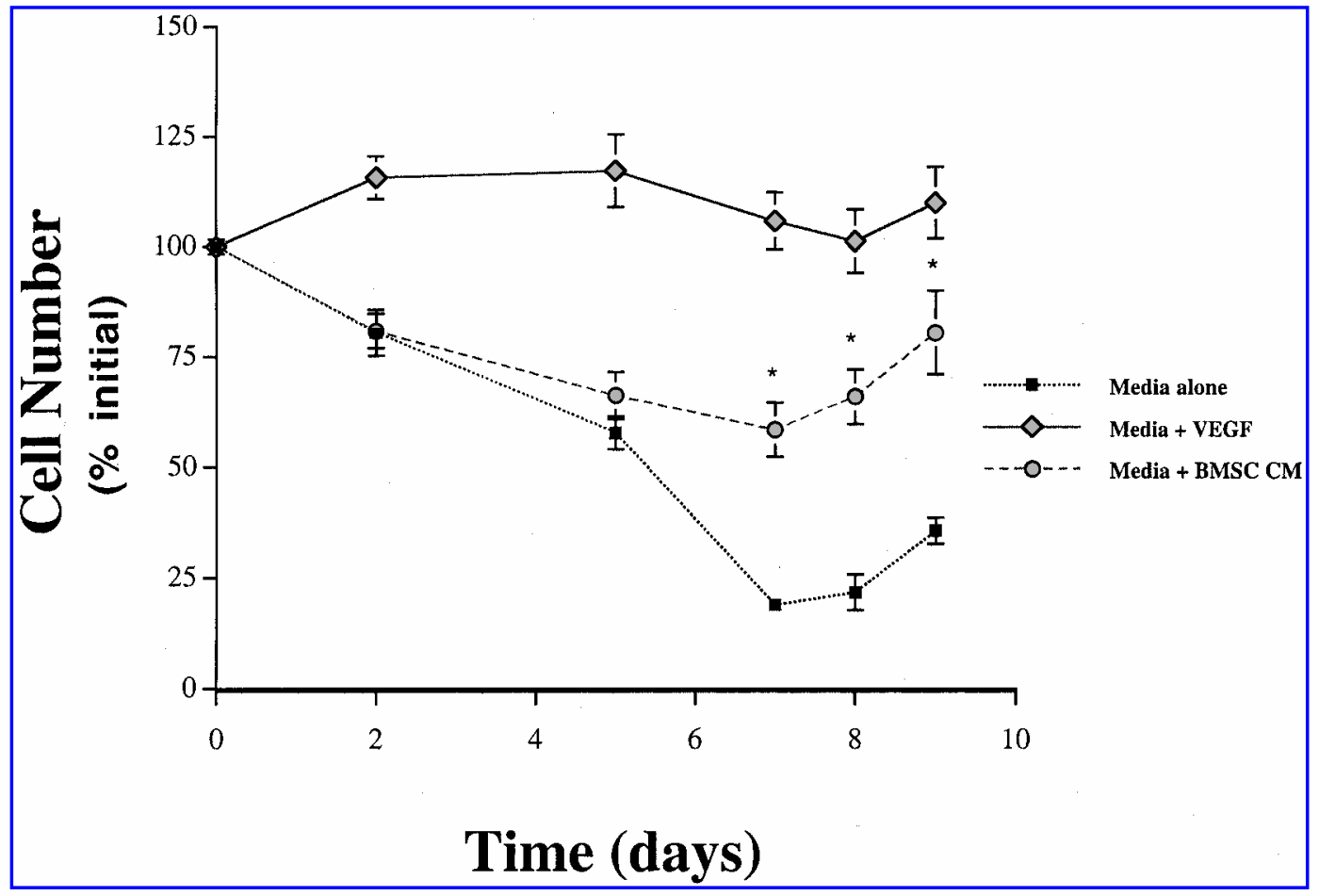

FIG. 1. Effect of BMSC CM on endothelial cell survival. ECs were cultured under three different conditions: medium alone, medium plus VEGF, and medium plus BMSC CM. Cell survival was measured as a percentage of the initial number of adherent cells per $\times 200$ field. Values represent means \pm standard error of the mean $(\mathrm{SEM})$ calculated from three dishes. ${ }^{*} p<0.05$ when compared with medium alone. 


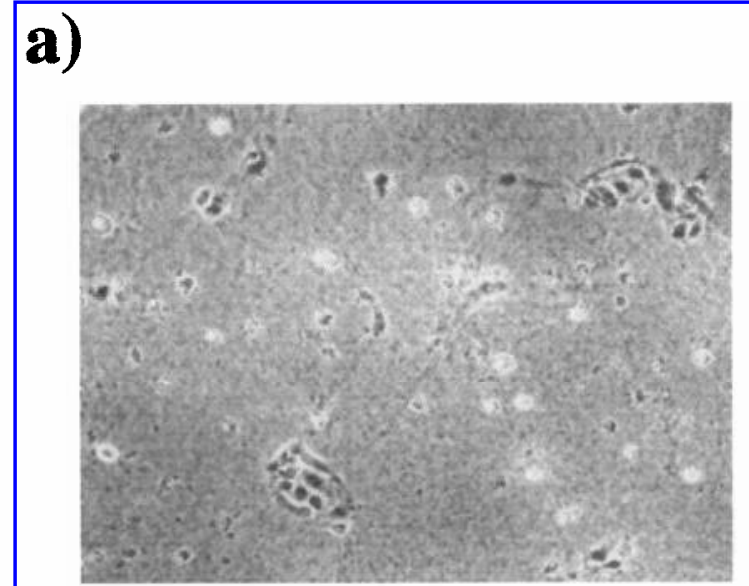

c)

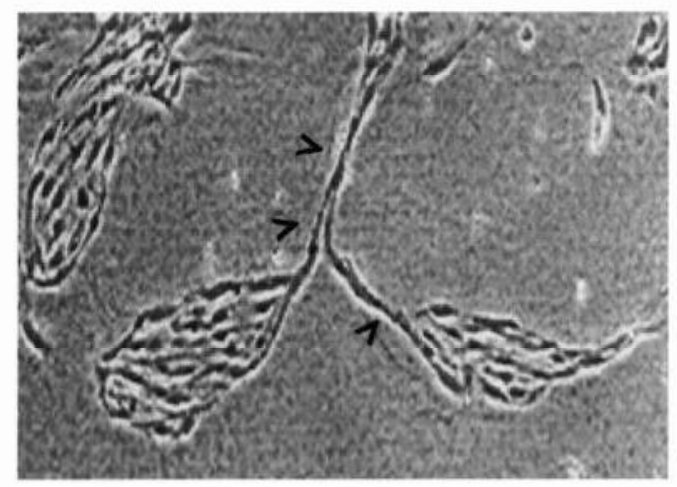

Day 7

\section{b)}

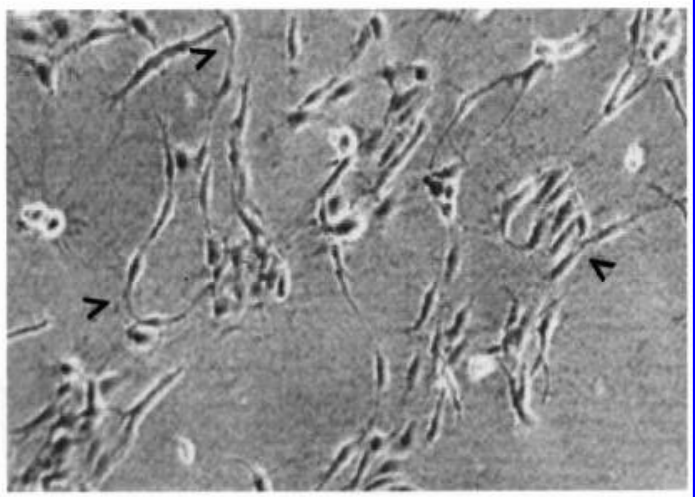

Day 5

d)

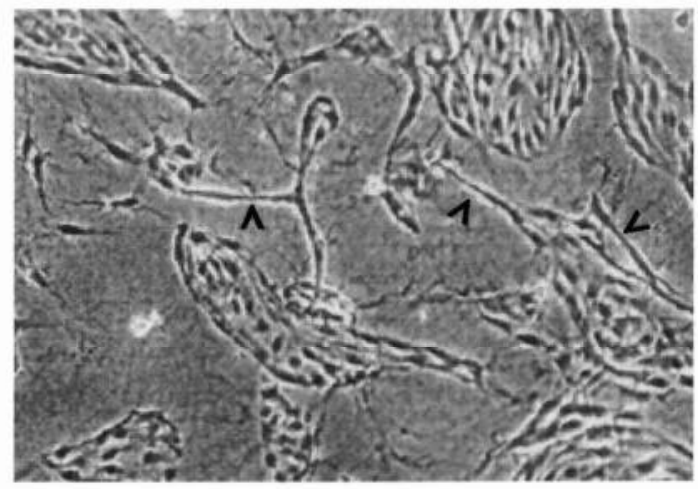

Day 10

FIG. 2. (a-d) Endothelial cell sprouting seen after induction with VEGF. ECs form sprouts, indicated by carets, after induction with rhVEGF. Day represents number of days after initial seeding of cells. The number of sprouts increases with time of exposure to VEGF. Original magnification: $\times 100$.

viously described, from patients undergoing iliac bone graft procedures. ${ }^{23}$ Briefly, marrow was placed in icecold $\alpha$-MEM (Life Technologies, Grand Island, NY) with sodium heparin $(100 \mathrm{U} / \mathrm{mL}$; Fisher Scientific, Fair Lawn, $\mathrm{NJ}$ ) and centrifuged at $1000 \mathrm{rpm}$ for $10 \mathrm{~min}$, and the cell pellet was resuspended in fresh $\alpha$-MEM. All preparations were pipetted repeatedly to break up cell aggregates. Subsequently, marrow cell suspensions were passed consecutively through 16.5- and 20.5-gauge needles before culture. Cells were cultured in $\alpha$-MEM, $2 \mathrm{mM}$ glutamine, penicillin $(100 \mathrm{U} / \mathrm{mL})$, streptomycin sulfate $(100 \mu \mathrm{g} / \mathrm{mL})$ (Biofluids, Rockville, MD), and 10\% fetal bovine serum (FBS; Life Technologies) supplemented with $10^{-8} \mathrm{M}$ dexamethasone (Dex; Sigma, St. Louis, MO) and $10^{-4} \mathrm{M}$ L-ascorbic acid-phosphated magnesium salt $n$-hydrate (AscP; Wako, Osaka, Japan).

Mouse bone marrow stromal cells (mBMSCs) were collected from B57Blk6 mice. Mice were sacrificed and washed in $80 \%$ ethanol. The limbs of each mouse were removed at their articulation and placed in a $100 \times$ $20 \mathrm{~mm}^{2}$ style tissue culture dish (Falcon; BD Diagnostic Systems, Franklin Lakes, NJ) with Hanks' balanced salt solution (HBSS; Life Technologies, Rockville, MD) and 2\% penicillin-streptomycin (P/S) (GIBCO-BRL, Gaithersburg, MD). Bone marrow was flushed from the femur and humerus bones with medium containing $20 \%$ FBS, $1 \% \mathrm{P} / \mathrm{S}$, and amphotericin B (Fungizone, diluted $1: 1000)$. All flushed marrow was then placed in $75-\mathrm{mm}^{2}$ tissue culture flasks (marrow from two mice per flask) (Corning Life Sciences, Corning, NY) with medium containing 20\% FBS, 1\% P/S, Fungizone (diluted 1:1000), and $10^{-8} \mathrm{M}$ Dex. After 1 week in $75-\mathrm{mm}^{2}$ tissue culture flasks incubated at $37^{\circ} \mathrm{C}$ in a humidified atmosphere of 95\% air and $5 \% \mathrm{CO}_{2}$, half of the medium volume was replaced with fresh medium. Three days after this initial change in medium, cells were passaged. Cells were main- 


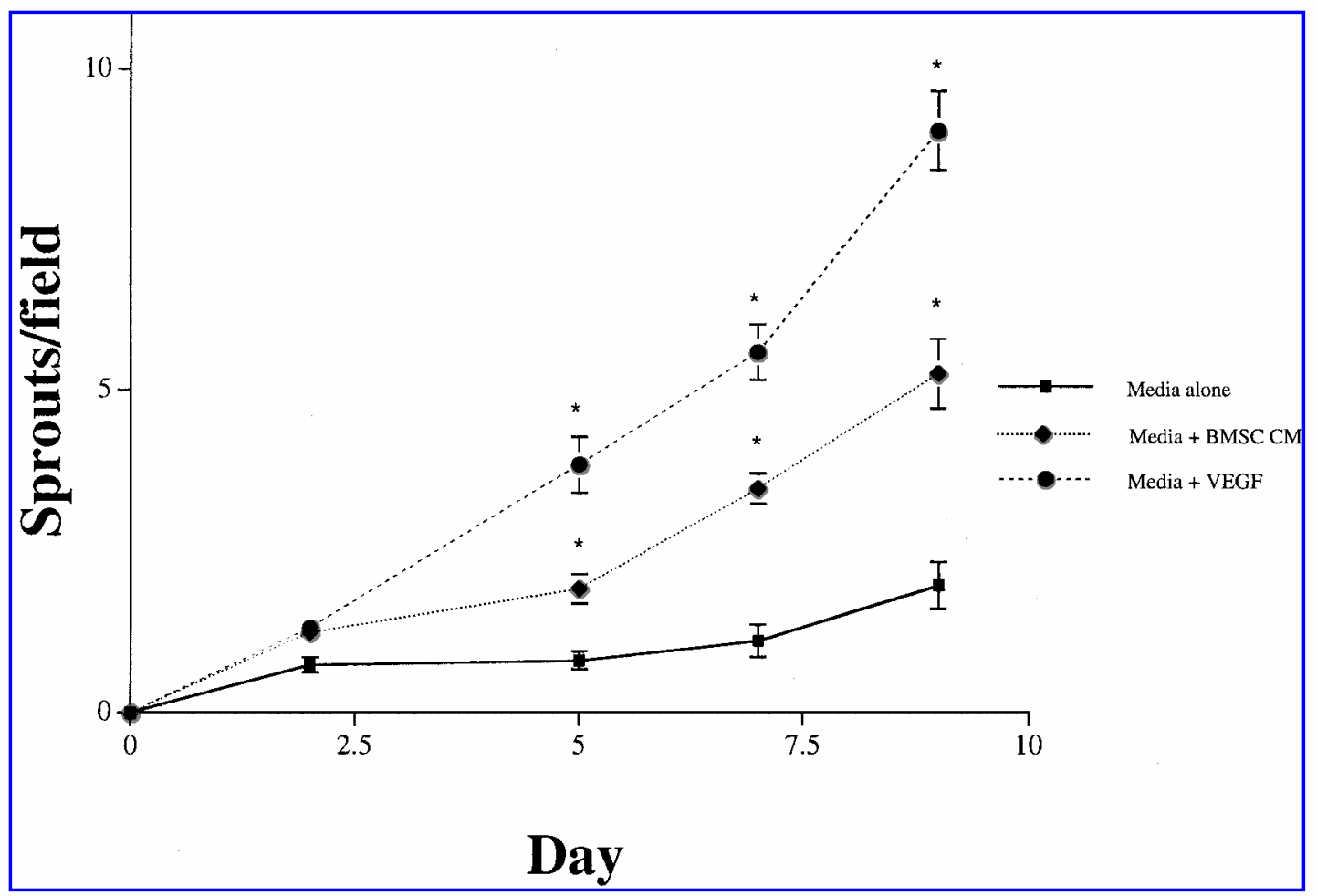

FIG. 3. Effects of BMSC CM on EC sprouting. EC sprouting is used as a marker of differentiation, and is measured as the average number of sprouts per $\times 100$ field. Values represent means $\pm \operatorname{SEM}(n=3) .{ }^{*} p<0.05$ when compared with medium alone.

tained in $\alpha$-MEM containing $10 \%$ FBS, $1 \% \mathrm{P} / \mathrm{S}$, and $10^{-8}$ M Dex.

Preosteoblastic MC3T3-E1 cells were a generous gift from M. Kumegawa (Josai Dental University, Sakado, Saitama, Japan). These cells were cultured in $\alpha$-MEM containing $10 \%$ fetal calf serum and $1 \% \mathrm{P} / \mathrm{S}$.

Normal human mesenchymal stem cells (hMSCs), generated via a Poietics system (BioWhittaker Cambrex, Walkersville, MD), were cultured in human mesenchymal stem cell growth medium (Clonetics, San Diego, $\mathrm{CA})$ as directed by the supplier.

\section{Endothelial cell survival and capillary tube assays}

Human dermal microvascular endothelial cells (HDMECs, $3.0 \times 10^{5}$; Cell Systems, Kirkland, WA) were suspended in endothelial cell growth medium (EGM-MV; Clonetics) and placed into $60-\mathrm{mm}^{2}$ tissue culture dishes (Corning Life Sciences). Dishes were coated $24 \mathrm{~h}$ earlier with $2.5 \mathrm{~mL}$ of a gelled solution of bovine dermal type I collagen (Vitrogen 100; Cohesion, Palo Alto, CA). Cells were allowed to attach for $24 \mathrm{~h}$, plates were washed to remove unattached cells, and cells were cultured in EGM-MV, supplemented with either recombinant human VEGF $_{165}\left(\mathrm{rhVEGF}_{165}, 50 \mathrm{ng} / \mathrm{mL}\right.$; Intergen, Purchase, NY), BMSC conditioned medium
(CM), or endothelial basal medium (EBM-2; Clonetics) with $1 \%$ FBS used as the control medium. All BMSC $\mathrm{CM}$ used in the survival and capillary tube assays was collected from cultures of human BMSCs isolated as described earlier. The BMSC CM was collected and concentrated 10 -fold by centrifugation with an UltraFree-15 centrifugal filter device, which had a membrane with a nominal molecular mass limit of $5 \mathrm{kDa}$ (Millipore, Bedford, MA). The concentrated medium was then brought back to a $1 \times$ concentration by diluting it 1:10 with EGMMV (normal EC growth medium) before addition to EC cultures. The control medium (not exposed to BMSCs) was similarly concentrated and diluted with EGM-MV before use. Each respective medium was exchanged for fresh medium, of the same type, every 2 days for the duration of the experiment. Every other day for 9 or 10 days, the number of cells in 8 random high-power fields $(\times 200)$, as well as the number of capillary-like sprouts in 10 random high-powered fields $(\times 100)$, were counted. Criteria for counting sprouts have been previously described. ${ }^{24}$ The criteria used to define a sprout in these assays were at least two endothelial cells connecting to one another by an elongated branching structure from one or both of the cells. The data were obtained from triplicate dishes per condition at each time point.

In certain experiments, ECs were cultured in BMSC CM containing mouse anti-human VEGF Ab-3 (JH121; 


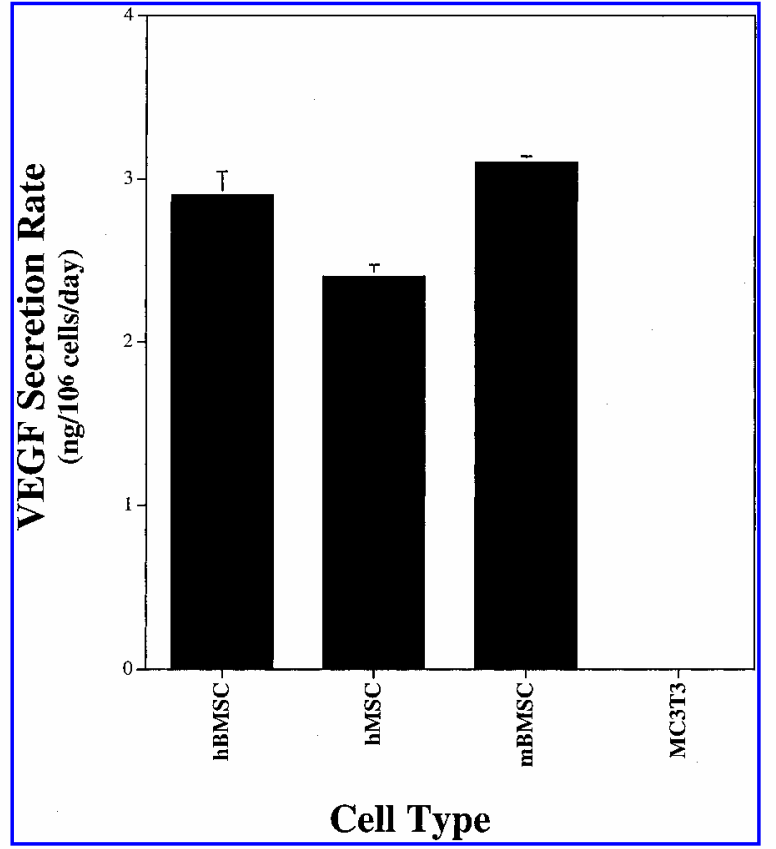

FIG. 4. Quantitative measurement of VEGF in medium (in human BMSC CM, human MSC CM, mouse BMSC CM, and $\mathrm{CM}$ from an osteoblastic cell line, MC3T3-E1). ELISA was used to determine concentrations of VEGF. Concentrations were normalized to cell number and secretion time. Values represent means \pm SEM.
Neomarkers, Fremont, CA) or mouse IgG1 Ab-2 (Neomarkers). The anti-VEGF antibody used in this assay inhibits the biological activity of human VEGF, and inhibits the biological activity of mouse, rat, and rabbit VEGF as well (Neomarkers, company literature). EC survival and sprout formation were measured as described above.

\section{Quantitative measurement of VEGF in CM}

At approximately $95 \%$ confluence, hBMSCs, mBMSCs, hMSCs, and MC3T3-E1 cells (all between passages 5 and 7) were washed twice with HBSS and placed in EBM-2 with $1 \%$ fetal bovine serum overnight (16 h). The medium was then collected and concentrated 10-fold with an UltraFree-15 centrifugal filter device (Millipore). Cell counts were obtained with a Coulter counter at the time of medium collection to normalize VEGF secretion to cell number. The VEGF concentration in hBMSC CM was measured by a solid-phase enzyme-linked immunosorbent assay (ELISA) (R\&D Systems, Minneapolis, MN) designed to measure VEGF levels in supernatants, serum, and plasma. VEGF concentration was measured in picograms per milliliter, and normalized per million cells (based on cell counts done using a Coulter counter at the time of collection of CM). The minimum detectable concentration of VEGF in this assay is $5.0 \mathrm{pg} / \mathrm{ml}$.

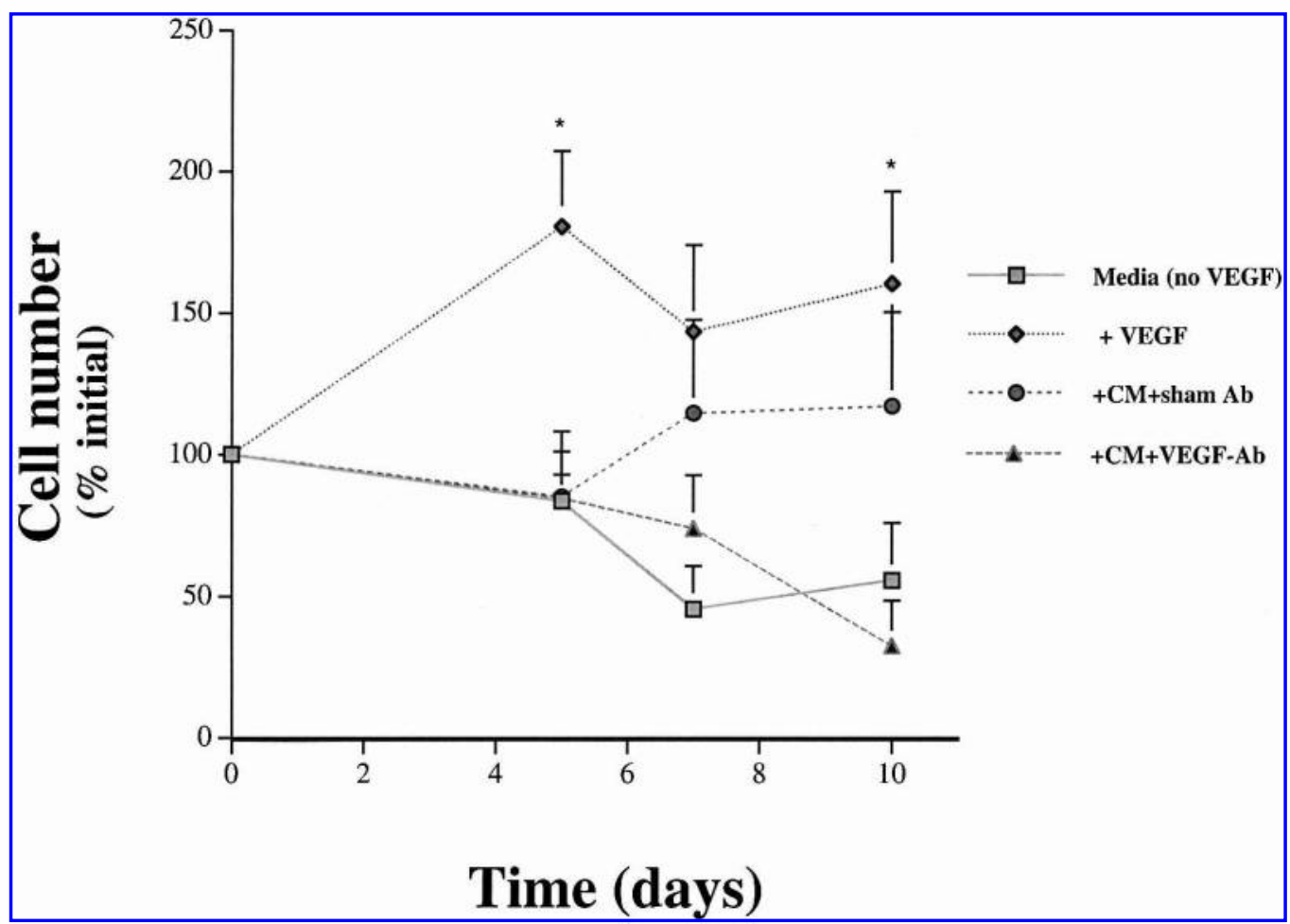

FIG. 5. VEGF antibody blocking of BMSC CM effects on EC survival. ECs were cultured under four different conditions: medium alone, medium plus VEGF antibody, medium plus BMSC CM plus VEGF antibody, and medium plus BMSC CM plus control $\mathrm{Ab}(\mathrm{IgG})$. Cell survival is measured as a percentage of the total number of cells initially adherent, and values represent means $\pm \operatorname{SEM}(n=3)$. Original magnification: $\times 200 .{ }^{*} p<0.05$ when compared with CM plus VEGF Ab. 


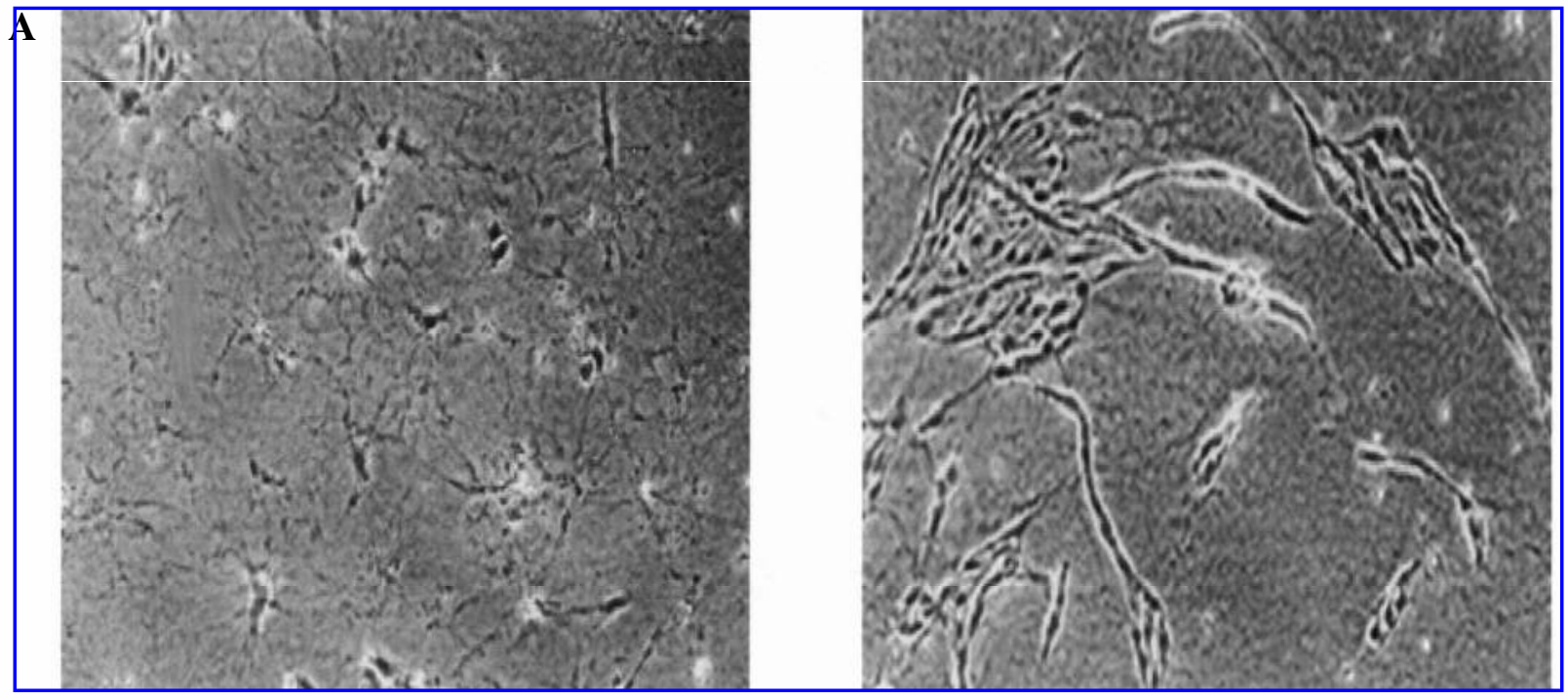

C

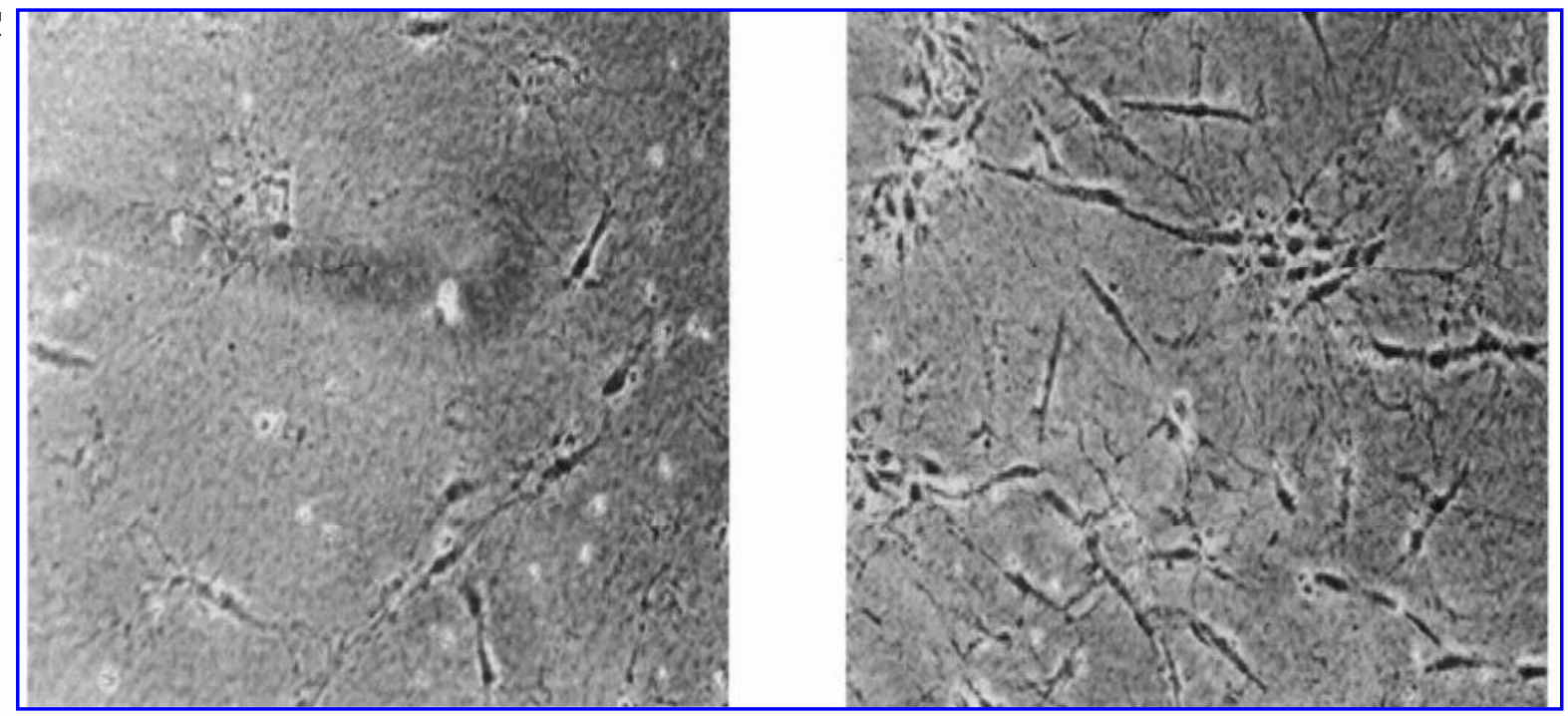

FIG. 6. Effect of VEGF blocking on BMSC CM promotion of EC differentiation. Photomicrographs of representative $\times 100$ fields were taken of ECs in culture (a-d) and the number of sprouts per $\times 100$ field was quantified (e). Four experimental conditions were tested: medium alone (a), medium plus VEGF (b), medium plus BMSC CM plus VEGF Ab (c), and medium plus BMSC CM plus IgG Ab (d). Values in (e) represent means $\pm \operatorname{SEM}(n=3) .{ }^{*} p<0.05$ when compared with medium alone.

\section{Statistical analysis}

The statistical analyses were performed with Sigma Stat (Sigma). Descriptive analyses were performed initially, followed by the use of Student $t$ tests or one-way ANOVA, according to the experimental design.

\section{RESULTS}

\section{Effects of BMSC CM on EC survival and differentiation}

To test whether BMSCs influence EC survival and differentiation, we cultured ECs in the presence of BMSC $\mathrm{CM}$ or the known proangiogenic factor VEGF. We com- pared the survival and differentiation effects of BMSC $\mathrm{CM}$ with the effects of VEGF. The addition of VEGF to EC cultures enhanced endothelial cell survival on collagen gels, whereas total cell number declined over time if cells were cultured in basal medium alone (Fig. 1). The addition of BMSC CM to endothelial cell cultures enhanced endothelial cell survival after 6 days in culture. At all time points after 7 days, the percentage of the initial number of ECs that remained in culture was significantly $(p<0.05)$ higher in cultures supplemented with BMSC CM, when compared with survival of endothelial cells cultured in nonsupplemented medium.

The ability of ECs to organize into sprouting structures is a hallmark of EC differentiation in vitro, ${ }^{25,26}$ and we 


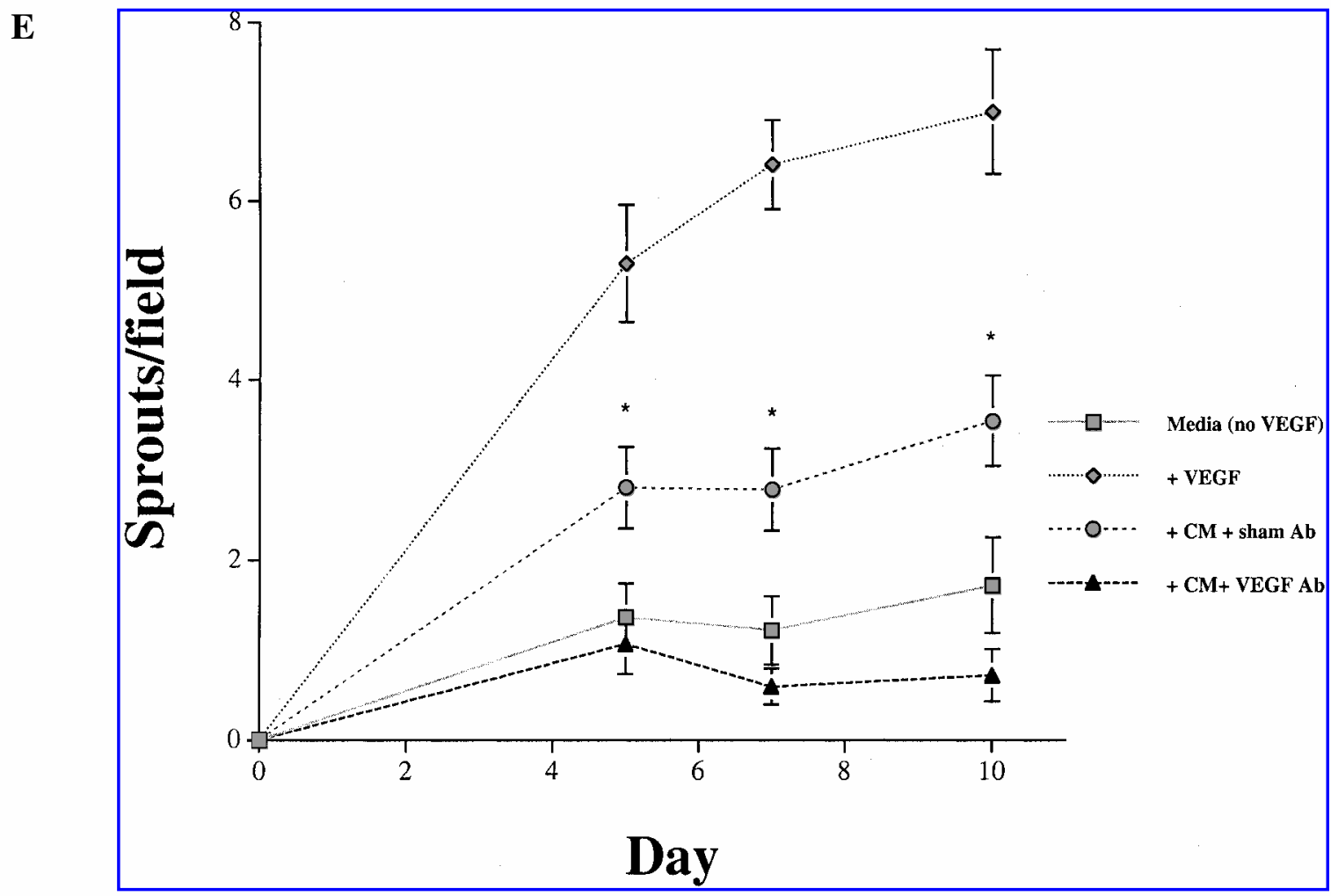

FIG. 6. Continued

used this marker to test the effects of BMSC CM on EC differentiation. We first tested our model system for in vitro angiogenesis by adding VEGF to EC cultures as a stimulus for EC differentiation. Over a 10-day time course during which VEGF was added to EC cultures, organization of ECs into capillary-like networks was clearly seen (Fig. 2). Small-scale screening assays utilizing different concentrations of VEGF indicated that $50 \mathrm{ng} / \mathrm{ml}$ gives the most robust sprouting response, particularly at late time points (i.e., 10-14 days) (data not shown), and this concentration was used as a positive control in all studies. Addition of BMSC CM to collagen cultures led to a significant enhancement $(p<0.05)$ in endothelial cell sprouting, beginning on day 5, when compared with levels of sprouting in cultures grown in basal medium alone. This effect continued for the 9-day duration of the experiment (Fig. 3).

\section{Role of VEGF in BMSC CM effects on ECs}

VEGF is a potent angiogenic factor produced by a variety of cell types and has been previously noted to be secreted from bone marrow-derived cells. ${ }^{13,14} \mathrm{We}$ investigated whether the effects of BMSC CM on ECs could be partially or totally attributed to secreted VEGF. First, ELISAs were performed with conditioned medium from four different types of stromal cells cultured overnight $(\sim 16 \mathrm{~h})$ in basal medium containing $1 \%$ serum to con- firm that the stromal cells used in these studies secreted VEGF. Human BMSCs, human mesenchymal stem cells, and mouse BMSCs all secreted VEGF at rates between 2.4 and $3.1 \mathrm{ng} / 10^{6}$ cells per day. A fourth cell type, the preosteoblastic cell line MC3T3-E1, did not secrete any detectable VEGF during this time period (Fig. 4). Quantifying VEGF in this manner also allowed us to make an estimate of the amount of VEGF that was contained in the CM, before addition of CM to ECs, in the survival and capillary tube assays. On the basis of the data quantifying secreted VEGF from hBMSCs, BMSC CM contained VEGF at $2 \mathrm{ng} / \mathrm{mL}$. Next, we determined whether VEGF in BMSC CM was responsible for the survival and differentiation effects seen with ECs. To do this, VEGF blocking and control antibodies were added to BMSC $\mathrm{CM}$ before addition of the medium to EC cultures. VEGF blocking antibodies completely eliminated the positive effects of BMSC CM on EC survival, whereas the control antibody had no effect (Fig. 5).

VEGF antibodies were also employed in the capillary tube assay to confirm the role of BMSC-secreted VEGF in EC differentiation. As expected, culture of ECs in basal medium led to little EC differentiation (Fig. 6a) and stimulation of cultures with VEGF produced the greatest magnitude of sprouting (Fig. 6b). BMSC CM plus control antibodies again demonstrated increased EC sprouting (Fig. 6d). However, this increase in endothelial cell 
sprouting was greatly reduced when VEGF-blocking antibodies were added to BMSC CM before addition to EC cultures (Fig. 6c). Quantification of these findings indicated that the levels of endothelial cell sprouting with BMSC CM were actually reduced to a lower level than control, after addition of VEGF Ab (Fig. 6e).

\section{DISCUSSION}

In these studies, we investigated the hypothesis that BMSCs could direct and modulate the growth and differentiation of ECs. We have shown that BMSCs from different sources (mouse/human) secrete VEGF. Furthermore, hBMSCs secrete sufficient factors to enhance the proliferation and differentiation of ECs in threedimensional collagen cultures. Finally, antibody blocking experiments confirmed that the effects of hBMSC $\mathrm{CM}$ on ECs is either completely attributable to secreted VEGF, or at least requires the action of secreted VEGF.

It has been previously reported that different types of osteogenic cells can be induced to express VEGF ${ }^{13,27}$ and that bone marrow cells secrete VEGF. ${ }^{14}$ However, this is the first report of secretion of VEGF from this population of cells, defined as BMSCs and characterized as previously described. ${ }^{17}$ VEGF in conditioned medium was measured by an ELISA and cells were counted after collection of conditioned medium to quantify the amount of VEGF secreted on a per-cell number basis. Quantification on a per-cell transplanted basis could potentially be useful in cell transplantation protocols in which the aim is to utilize these cells as a source of angiogenic factors. It could be of even greater significance if the plan is to augment secreted levels of growth factor from BMSCs with exogenous delivery of VEGF. A significant finding is that BMSCs secrete a sufficient quantity of functional angiogenic factors capable of enhancing the survival and differentiation of ECs. Furthermore, the amounts of VEGF secreted correlate with the mitogenic activity of VEGF. ${ }^{28}$ The sprouting assay used in this study is an in vitro model for angiogenesis in which ECs in culture have been shown to produce tubular networks almost identical, by light and electron microscopy, to capillary vascular beds in vivo. ${ }^{25} \mathrm{In}$ a similar system, ${ }^{29}$ it has also been shown that various concentrations of VEGF induce proliferation and much greater differentiation of endothelial cells into capillary tubes. ${ }^{30}$ In our studies, although hBMSC CM did not enhance proliferation and differentiation to levels seen when exogenous VEGF was added, there was a statistically significant enhancement of proliferation and differentiation over negative control levels. The decreased effect of BMSC CM was likely related to the lower concentration of VEGF in CM (2 ng/ml), as compared with the VEGF control $(50 \mathrm{ng} / \mathrm{ml})$. There have been reports of inducing angiogenesis through the transplantation of other types of bone marrow-derived cells ${ }^{14,31}$ and sug- gestions for these cells to be used therapeutically for angiogenesis. ${ }^{32,33}$ However, there have not been any reports quantifying the amount of VEGF secreted by hBMSCs, or describing their effects on EC survival and differentiation in the capillary tube assay.

The role of VEGF in BMSC CM-induced EC survival and differentiation was determined by antibody blocking experiments. Where previous studies have reported that supernatant from cultured bone marrow cells can enhance proliferation of ECs in vitro, ${ }^{14,31}$ our results further indicate that their effects are either completely attributable to secreted VEGF, or at least requires the action of secreted VEGF. VEGF-blocking antibodies eliminated the enhanced survival and differentiation found with the addition of hBMSC CM. We propose two possible mechanisms to explain this observation. The first is that VEGF secreted from hBMSCs is solely responsible for the heightened activity of ECs in the presence of CM. The other possibility is that VEGF functions in concert with additional secreted factors in order to enhance the survival and differentiation of ECs. Additional assays for detection of other growth factors and cytokines need to be carried out in order to better differentiate between these possible mechanisms.

In summary, we have demonstrated that hBMSCs secrete VEGF capable of enhancing the growth and differentiation of endothelial cells in an in vitro model of angiogenesis. The secreted VEGF is necessary, but not necessarily sufficient, for hBMSC CM to enhance EC survival and differentiation. This finding suggests hBMSC transplantation may allow the rapid achievement of vascularization of engineered tissues, although further in vivo studies are required to confirm this possibility. The finding of these studies also further the current understanding of the interactions between ECs and osteoprogenitor cells.

\section{ACKNOWLEDGMENTS}

The authors thank Jacques Nor and Christina Addison for technical assistance. The authors are grateful to the NIDCR for funding of an Individual Pre-doctoral Dental Scientist Fellowship (F30 DE05747) to D.K., and for research funding to the laboratories of P.K. (RO1DE013835) and D.M. (RO1-DE13033).

\section{REFERENCES}

1. Langer, R., and Vacanti, J.P. Tissue engineering. Science 260, 920, 1993.

2. Folkman, J. Angiogenesis and angiogenesis inhibition: An overview. EXS 79, 1, 1997.

3. Mooney, D.J., Sano, K., Kaufmann, P.M., Majahod, K., Schloo, B., Vacanti, J.P., and Langer, R. Long-term engraftment of hepatocytes transplanted on biodegradable polymer sponges. J. Biomed. Mater. Res. 37, 413, 1997. 
4. Folkman, J., and Cotran, R. Relation of vascular proliferation to tumor growth. Int. Rev. Exp. Pathol. 1, 207, 1976.

5. Klagsbrun, M., and D'Amore, P.A. Regulators of angiogenesis. Annu. Rev. Physiol. 53, 217, 1991.

6. Polverini, P.J. The pathophysiology of angiogenesis. Crit. Rev. Oral Biol. Med. 6, 230, 1995.

7. Ferrara, N. Vascular endothelial growth factor. Eur. J. Cancer 32A, 2413, 1996.

8. Kryger, Z., Dogan, T., Zhang, F., Komorowska-Timek, E., Shi, D.Y., Cheng, C., Lineaweaver, W.C., and Buncke, H.J. Effects of VEGF administration following ischemia on survival of the gracilis muscle flap in the rat. Ann. Plast. Surg. 43, 172, 1999.

9. Kryger, Z., Zhang, F., Dogan, T., Cheng, C., Lineaweaver, W.C., and Buncke, H.J. The effects of VEGF on survival of a random flap in the rat: Examination of various routes of administration. Br. J. Plast. Surg. 53, 234, 2000.

10. Murphy, W.L., Peters, M.C., Kohn, D.H., and Mooney, D.J. Sustained release of vascular endothelial growth factor from mineralized poly(lactide-co-glycolide) scaffolds for tissue engineering. Biomaterials 21, 2521, 2000.

11. Lee, K.Y., Peters, M.C., Anderson, K.W., and Mooney, D.J. Controlled growth factor release from synthetic extracellular matrices. Nature 408, 998, 2000.

12. Sheridan, M.H., Shea, L.D., Peters, M.C., and Mooney, D.J. Bioabsorbable polymer scaffolds for tissue engineering capable of sustained growth factor delivery. J. Control. Release 64, 91, 2000.

13. Harada, S., Nagy, J.A., Sullivan, K.A., Thomas, K.A., Endo, N., Rodan, G.A., and Rodan, S.B. Induction of vascular endothelial growth factor expression by prostaglan$\operatorname{din} \mathrm{E}_{2}$ and $\mathrm{E}_{1}$ in osteoblasts. J. Clin. Invest. 93, 2490, 1994.

14. Fuchs, S., Baffour, R., Zhou, Y.F., Shou, M., Pierre, A., Tio, F.O., Weissman, N.J., Leon, M.B., Epstein, S.E., and Kornowski, R. Transendocardial delivery of autologous bone marrow enhances collateral perfusion and regional function in pigs with chronic experimental myocardial ischemia. J. Am. Coll. Cardiol. 37, 1726, 2001.

15. Ishaug-Riley, S.L., Crane, G.M., Gurlek, A., Miller, M.J., Yasko, A.W., Yaszemski, M.J., and Mikos, A.G. Ectopic bone formation by marrow stromal osteoblast transplantation using poly (DL-lactic-co-glycolicacid) foams implanted into the rat mesentery. J. Biomed. Mater. Res. 36, 1, 1997.

16. Yamagiwa, H., Endo, N., Tokunaga, K., Hayami, T., Hatano, H., and Takahashi, H.E. In vivo bone-forming capacity of human bone marrow-derived stromal cells is stimulated by recombinant human bone morphogenetic protein2. J. Bone Miner. Metab. 19, 20, 2001.

17. Gao, J., Dennis, J.E., Solchaga, L.A., Awadallah, A.S., Goldberg, V.M., and Caplan, A.I. Tissue-engineered fabrication of an osteochondral composite graft using rat bone marrow-derived mesenchymal stem cells. Tissue Eng. 7, 363, 2001.

18. Friedenstein, A.J., Ivanov-Smolenski, A.A., Chajlakjan, R.K., Gorskaya, U.F., Kuralesova, A.I., Latzinik, N.W., and Gerasimow, U.W. Origin of bone marrow stromal mechanocytes in radiochimeras and heterotopic transplants. Exp. Hematol. 6, 440, 1978.

19. Latsinik, N.V., Gorskaia, I.F., Grosheva, A.G., Domogatskii, S.P., and Kuznetsov, S.A. [The stromal colonyforming cell (CFUf) count in the bone marrow of mice and the clonal nature of the fibroblast colonies they form]. Ontogenez 17, 27, 1986.

20. Krebsbach, P.H., Kuznetsov, S.A., Bianco, P., and Robey, P.G. Bone marrow stromal cells: Characterization and clinical application. Crit. Rev. Oral Biol. Med. 10, 165, 1999.

21. Haynesworth, S.E., Goshima, J., Goldberg, V.M., and Caplan, A.I. Characterization of cells with osteogenic potential from human marrow. Bone 13, 81, 1992.

22. Caplan, A.I. Mesenchymal stem cells. J. Orthop. Res. 9, 641, 1991.

23. Krebsbach, P.H., Kuznetsov, S.A., Satomura, K., Emmons, R.V., Rowe, D.W., and Robey, P.G. Bone formation in vivo: Comparison of osteogenesis by transplanted mouse and human marrow stromal fibroblasts. Transplantation 63, 1059, 1997.

24. DiPietro, L.A., Nebgen, D.R., and Polverini, P.J. Downregulation of endothelial cell thrombospondin 1 enhances in vitro angiogenesis. J. Vasc. Res. 31, 178, 1994.

25. Folkman, J., and Haudenschild, C. Angiogenesis in vitro. Nature 288, 551, 1980.

26. Montesano, R., Orci, L., and Vassalli, P. In vitro rapid organization of endothelial cells into capillary-like networks is promoted by collagen matrices. J. Cell Biol. 97, 1648, 1983.

27. Steinbrech, D.S., Mehrara, B.J., Saadeh, P.B., Greenwald, J.A., Spector, J.A., Gittes, G.K., and Longaker, M.T. VEGF expression in an osteoblast-like cell line is regulated by a hypoxia response mechanism. Am. J. Physiol. Cell Physiol. 278, C853, 2000.

28. Ferrara, N., and Davis-Smyth, T. The biology of vascular endothelial growth factor. Endocr. Rev. 18, 4, 1997.

29. Villaschi, S., and Nicosia, R.F. Paracrine interactions between fibroblasts and endothelial cells in a serum-free coculture model: Modulation of angiogenesis and collagen gel contraction. Lab. Invest. 71, 291, 1994.

30. Nor, J.E., Christensen, J., Mooney, D.J., and Polverini, P.J. Vascular endothelial growth factor (VEGF)-mediated angiogenesis is associated with enhanced endothelial cell survival and induction of Bcl-2 expression. Am. J. Pathol. 154, 375, 1999.

31. Hamano, K., Li, T.S., Kobayashi, T., Kobayashi, S., Matsuzaki, M., and Esato, K. Angiogenesis induced by the implantation of self-bone marrow cells: A new material for therapeutic angiogenesis. Cell Transplant. 9, 439, 2000.

32. Carmeliet, P., and Luttun, A. The emerging role of the bone marrow-derived stem cells in (therapeutic) angiogenesis. Thromb. Haemost. 86, 289, 2001.

33. Epstein, S.E., Fuchs, S., Zhou, Y.F., Baffour, R., and Kornowski, R. Therapeutic interventions for enhancing collateral development by administration of growth factors: Basic principles, early results and potential hazards. Cardiovasc. Res. 49, 532, 2001.

Address reprint requests to: David J. Mooney, Ph.D.

Department of Biologic and Materials Sciences University of Michigan $1011 \mathrm{~N}$. University Ann Arbor, MI 48109-1078

E-mail: mooneyd@engin.umich.edu 


\section{This article has been cited by:}

1. K. Otsu, S. Das, S. D. Houser, S. K. Quadri, S. Bhattacharya, J. Bhattacharya. 2009. Concentration-dependent inhibition of angiogenesis by mesenchymal stem cells. Blood 113:18, 4197-4205. [CrossRef]

2. Richard A. Hopper, Jon P. VerHalen, Oren Tepper, Babek J. Mehrara, Robert Detch, Edward I. Chang, Samuel Baharestani, Bruce J. Simon, Geoffrey C. Gurtner. 2009. Osteoblasts stimulated with pulsed electromagnetic fields increase HUVEC proliferation via a VEGF-A independent mechanism. Bioelectromagnetics 30:3, 189-197. [CrossRef]

3. Meng Liu, Zhong Chao Han. 2008. Mesenchymal stem cells: biology and clinical potential in type 1 diabetes therapy. Journal of Cellular and Molecular Medicine 12:4, 1155-1168. [CrossRef]

4. Mani T. Valarmathi, Michael J. Yost, Richard L. Goodwin, Jay D. Potts . 2008. A Three-Dimensional Tubular Scaffold that Modulates the Osteogenic and Vasculogenic Differentiation of Rat Bone Marrow Stromal CellsA Three-Dimensional Tubular Scaffold that Modulates the Osteogenic and Vasculogenic Differentiation of Rat Bone Marrow Stromal Cells. Tissue Engineering Part A 14:4, 491-504. [Abstract] [PDF] [PDF Plus]

5. Jason D. Roh , Gregory N. Nelson , Brooks V. Udelsman , Matthew P. Brennan , Britt Lockhart , Peter M. Fong, Reynold I. Lopez-Soler, W. Mark Saltzman , Christopher K. Breuer . 2007. Centrifugal Seeding Increases Seeding Efficiency and Cellular Distribution of Bone Marrow Stromal Cells in Porous Biodegradable ScaffoldsCentrifugal Seeding Increases Seeding Efficiency and Cellular Distribution of Bone Marrow Stromal Cells in Porous Biodegradable Scaffolds. Tissue Engineering 13:11, 2743-2749. [Abstract] [PDF] [PDF Plus]

6. Colm Morrissey, Robert L. Vessella. 2007. The role of tumor microenvironment in prostate cancer bone metastasis. Journal of Cellular Biochemistry 101:4, 873-886. [CrossRef]

7. R d'Aquino, A Graziano, M Sampaolesi, G Laino, G Pirozzi, A De Rosa, G Papaccio. 2007. Human postnatal dental pulp cells co-differentiate into osteoblasts and endotheliocytes: a pivotal synergy leading to adult bone tissue formation. Cell Death and Differentiation 14:6, 1162-1171. [CrossRef]

8. Kaigang Zhang, Bingfang Zeng, Changqing Zhang. 2007. Visualization of vascular ultrastructure during osteogenesis by tissue engineering technique. Frontiers of Medicine in China 1:2, 181-184. [CrossRef]

9. Grit Kasper, Niels Dankert, Jens Tuischer, Moritz Hoeft, Timo Gaber, Juliane D. Glaeser, Desiree Zander, Miriam Tschirschmann, Mark Thompson, Georg Matziolis, Georg N. Duda. 2007. Mesenchymal Stem Cells Regulate Angiogenesis According to Their Mechanical Environment. Stem Cells 25:4, 903-910. [CrossRef]

10. Inho Jo, Jung Min Lee, Hwal Suh, Hyongbum Kim. 2007. Bone tissue engineering using marrow stromal cells. Biotechnology and Bioprocess Engineering 12:1, 48-53. [CrossRef]

11. Erik Fink Eriksen, Guiti Z Eghbali-Fatourechi, Sundeep Khosla. 2007. Remodeling and Vascular Spaces in Bone. Journal of Bone and Mineral Research 22:1, 1-6. [CrossRef]

12. Yeon Kim, Hoe Kim, Hyun Cho, Yong Bae, Kuen Suh, Jin Jung. 2007. Direct Comparison of Human Mesenchymal Stem Cells Derived from Adipose Tissues and Bone Marrow in Mediating Neovascularization in Response to Vascular Ischemia. Cellular Physiology and Biochemistry 20:6, 867-876. [CrossRef]

13. Jeroen Rouwkema , Jan De Boer , Clemens A. Van Blitterswijk . 2006. Endothelial Cells Assemble into a 3-Dimensional Prevascular Network in a Bone Tissue Engineering ConstructEndothelial Cells Assemble into a 3-Dimensional Prevascular Network in a Bone Tissue Engineering Construct. Tissue Engineering 12:9, 2685-2693. [Abstract] [PDF] [PDF Plus]

14. Kristen A. Wieghaus, Scott M. Capitosti, Christopher R. Anderson, Richard J. Price, Brett R. Blackman, Milton L. Brown, Edward A. Botchwey. 2006. Small Molecule Inducers of Angiogenesis for Tissue Engineering. Tissue Engineering, ahead of print060706073730072. [CrossRef]

15. Kristen A. Wieghaus, Scott M. Capitosti , Christopher R. Anderson, Richard J. Price , Brett R. Blackman , Milton L. Brown , Edward A. Botchwey . 2006. Small Molecule Inducers of Angiogenesis for Tissue 
EngineeringSmall Molecule Inducers of Angiogenesis for Tissue Engineering. Tissue Engineering 12:7, 1903-1913. [Abstract] [PDF] [PDF Plus]

16. Susan X. Hsiong, David J. Mooney. 2006. Regeneration of vascularized bone. Periodontology 2000 41:1, 109-122. [CrossRef]

17. Kristen A. Wieghaus, Scott M. Capitosti, Christopher R. Anderson, Richard J. Price, Brett R. Blackman, Milton L. Brown, Edward A. Botchwey. 2006. Small Molecule Inducers of Angiogenesis for Tissue Engineering. Tissue Engineering, ahead of print060802052515050. [CrossRef]

18. Hiroshi Matsunuma, Hideaki Kagami, Yuji Narita, Ken-Ichiro Hata, Yoshonari Ono, Shinichi Ohshima, Minoru Ueda. 2006. Constructing a Tissue-Engineered Ureter Using a Decellularized Matrix with Cultured Uroepithelial Cells and Bone Marrow-Derived Mononuclear Cells. Tissue Engineering, ahead of print060315062947001. [CrossRef]

19. Jennifer M. Capla, Daniel J. Ceradini, Oren M. Tepper, Matthew J. Callaghan, Kirit A. Bhatt, Robert D. Galiano, Jamie P. Levine, Geoffrey C. Gurtner. 2006. Skin Graft Vascularization Involves Precisely Regulated Regression and Replacement of Endothelial Cells through Both Angiogenesis and Vasculogenesis. Plastic and Reconstructive Surgery 117:3, 836-844. [CrossRef]

20. Hiroshi Matsunuma, Hideaki Kagami , Yuji Narita, Ken-Ichiro Hata, Yoshonari Ono, Shinichi Ohshima , Minoru Ueda . 2006. Constructing a Tissue-Engineered Ureter Using a Decellularized Matrix with Cultured Uroepithelial Cells and Bone Marrow-Derived Mononuclear CellsConstructing a Tissue-Engineered Ureter Using a Decellularized Matrix with Cultured Uroepithelial Cells and Bone Marrow-Derived Mononuclear Cells. Tissue Engineering 12:3, 509-518. [Abstract] [PDF] [PDF Plus]

21. M. Markowicz, A. Heitland, G. C. M. Steffens, S. Neuss, N. Pallua. 2005. Human mesenchymal stem cell implantation and collagen modification as a tool for tissue engineering. European Journal of Plastic Surgery 28:4, 284-289. [CrossRef]

22. Enrico Lucarelli, Milena Fini, Amira Beccheroni, Gianluca Giavaresi, Claudia Di Bella, Nicol?? Nicoli Aldini, Gaetano Guzzardella, Lucia Martini, Annarita Cenacchi, Nunzia Di Maggio, Luca Sangiorgi, Pier Maria Fornasari, Mario Mercuri, Roberto Giardino, Davide Donati. 2005. Stromal Stem Cells and Platelet-Rich Plasma Improve Bone Allograft Integration. Clinical Orthopaedics and Related Research \&amp;NA;:435, 62-68. [CrossRef]

23. Yen-Chen Huang, Darnell Kaigler, Kevin G Rice, Paul H Krebsbach, David J Mooney. 2005. Combined Angiogenic and Osteogenic Factor Delivery Enhances Bone Marrow Stromal Cell-Driven Bone Regeneration. Journal of Bone and Mineral Research 20:5, 848-857. [CrossRef]

24. Reinhard Gruber, Barbara Kandler, Phillip Holzmann, Margit Vögele-Kadletz, Udo Losert , Michael B. Fischer , Georg Watzek . 2005. Bone Marrow Stromal Cells Can Provide a Local Environment That Favors Migration and Formation of Tubular Structures of Endothelial CellsBone Marrow Stromal Cells Can Provide a Local Environment That Favors Migration and Formation of Tubular Structures of Endothelial Cells. Tissue Engineering 11:5-6, 896-903. [Abstract] [PDF] [PDF Plus] 